\title{
The development of the parental feeding behaviours questionnaire for Indonesian parents with toddlers: preliminary result
}

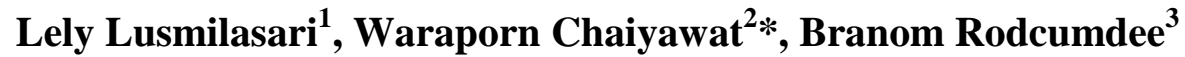
${ }^{1} \mathrm{PhD}$ Candidate, ${ }^{2}$ Associate Professor, ${ }^{3}$ Assistant Professor, Faculty of Nursing, Chulalongkorn University, Bangkok,
Thailand

Received: 19 August 2015

Accepted: 24 September 2015

*Correspondence:

Assoc. Prof. Waraporn Chaiyawat,

E-mail: waraporn.chaiyawat@gmail.com

Copyright: (c) the author(s), publisher and licensee Medip Academy. This is an open-access article distributed under the terms of the Creative Commons Attribution Non-Commercial License, which permits unrestricted non-commercial use, distribution, and reproduction in any medium, provided the original work is properly cited.

\begin{abstract}
Background: An accurate assessment of parents feeding behaviors is needed to determine current feeding behaviors of parents that are closely associated with the fulfillment of their toddlers' nutritional needs. This study aims to develop an instrument, the Parental Feeding Behaviors Questionnaire (PFBQ), for measuring feeding behaviors of Indonesian parents with toddlers.

Methods: An initial seventy-item instrument was developed after a comprehensive literature review which was submitted to be reviewed by six experts to evaluate the content validity of the PFBQ. The pre-test study was conducted by a convenience sampling of 30 parents who have toddlers both in urban and rural area in Yogyakarta, Indonesian for the first draft of 80-item instrument. Initial item analysis was measured using inter-item correlation, inter-total correlation and Cronbach's alpha.

Results: The PFBQ is the ways that Indonesian parents do that consist of three dimensions which are to provide healthy food, provide pleasant eating environment for their toddlers, as well as enhance the toddlers' good eating behaviors. The score of the Content Validity Index of the PFBQ is I-CVI (.83-1.00) and S-CVI (.98). Most of the items have acceptable inter-item correlation value (>.3). There are 56 items that are correlated with the total scores which range .30 to .62 . The value of Cronbach's alpha is .94 .

Conclusions: The PFBQ shows initial reliability and validity to assess the parental feeding behaviours for their toddlers. However, further testing is needed to test construct validity and reliability with a large sample for the improvement of the instrument.
\end{abstract}

Keywords: Instrument development, Parental feeding behaviours, Preliminary result

\section{INTRODUCTION}

Maintaining an adequate food intake in preschool age, including toddlers, is essential since they are still in their rapid growth and development period. Moreover, this period is also the time when eating behaviors can serve as foundations for future eating patterns to develop. Inadequate nutrition fulfillment in children requires special attention due to impact on increasing the nutritional problems that will lead to the increased morbidity and mortality, decreased intelligence and barriers to growth and development. ${ }^{1-2}$ This issue becomes more complex because Indonesia is facing double burden of nutritional problem. Indonesia still has a lot of under nutrition cases, while at the same time, cases in children with overweight and obesity are still increasing. ${ }^{3}$

Parents' feeding behaviors are closely associated with the fulfillment of children nutritional needs since children have some limitations in expressing and meeting their needs. ${ }^{4}$ In terms of nutrition intake, parental feeding 
behavior plays an important role in creating children's eating experiences and how it would link to children's eating behavior and nutritional status. ${ }^{5-10}$ Inappropriate parents' feeding behaviors will lead not only to underweight but also to overweight problems. ${ }^{6-8,10}$ Additionally, children whose parents have poor feeding practice are likely more prone to some health problems. ${ }^{11-}$

Parental feeding behaviors, which are the activities of parents in maintaining adequate food intake for their toddlers, involve more than just feeding activities. Acquiring information about foods, making food-buying decisions, and planning decision to serve healthy food may be the important cognitive activities prior to feeding activities. ${ }^{14}$ In this study the parental feeding behaviors are the ways Indonesian parents provide healthy food and pleasant eating environment to their toddlers, as well as enhance the toddlers' good eating behaviors. They need to acquire and gather information, and make judgment and decision before taking those action.

Recently, there are very limited valid and reliable instruments to measure feeding behaviors of parents both in community and hospital. The latest study showed that the assessment about the feeding behaviors of parents with toddlers focused only on the dimensions related to food consumption and parental feeding style. ${ }^{15-18}$ Although, the Parents Nutrition Dependent-Care Questionnaire (PNDCQ) seems to have a broader scope of parental feeding behaviors, it was developed for measuring nutrition behaviors that parents performed for their adolescent children. Nutritional needs for toddlers and for adolescents are different, thus, feeding behaviors that parents perform on the behalf of adolescent children are different from those performing for their toddlers. The PNDCQ, therefore, cannot be applied to parents of toddlers. $^{14}$

The present study aims to develop a new instrument and initially validate the Parental Feeding Behaviors Questionnaire (PFBQ) to measure feeding behaviors of Indonesian parents with toddlers. In order to have a reliable and valid instrument, commonly there are two phases of instrument development namely scale construction and psychometric testing phase. Current report only consists of scale construction phase. The psychometric properties testing on large sample has been conducted and will be published soon. The first step in construction phase is generating an item pool based on literature review. The next step is content validation by expert review. ${ }^{19-22}$ Furthermore, pre-testing of the scale should be conducted in initial analysis of item pool. The result of the study will provide information regarding items to measure feeding behaviors of parents.

\section{METHODS}

This study was instrument development study that used the modification of the guideline of DeVellis (2003),
Mishel (1998) and Benson and Clark (1982) as the process for developing the Parental Feeding Behaviors Questionnaire (PFBQ). ${ }^{19-21}$ This study was preliminary development of PFBQ in the construction phase consisted of three steps: generating an item pool, content validity by expert reviews, and an initial item analysis through pre-test study.

Generating an item pool. Generating an item pool was started by identifying operational definition of the parental feeding behaviors of parents with toddlers. To encompass the multiple dimensions of the parental feeding behaviors, this study used theoretical framework comprised of elements of the Orem's Dependent-care deficit nursing theory, parental feeding and toddlers' nutrition. ${ }^{4,23-25}$ Based on the result of the extensive literature review, the definition of parental feeding behaviors of parents was the ways Indonesian parents provide healthy food and pleasant eating environment to their toddlers, as well as enhance the toddlers' good eating behaviors which they need to acquire and gather information and make judgement and decision before taking those actions. Hence, there are three dimensions within parental feeding behaviors in this study.

In order to cover all dimensions of the operational definitions, a pool of 70 items which reflected all aspects of the feeding behaviors of Indonesian parents with toddlers namely providing healthy food (28 items); enhancing toddlers' good eating behaviors (25items); and providing a pleasant eating environment (17 items) was drafted. All items were expected to be representative items of the PFBQ for Indonesian parents with toddlers in general. This scale was designed as a self-report instrument, which consisted of three dimensions that were arranged in positive and negative wording to reduce the potential response of parents' answer with statement. This scale used the Likert-type scale in which this scale is commonly used in public health evaluation, especially in measuring opinion, belief, attitudes or behaviors items. Response choices in a Likert-scale most commonly address agreement, evaluation, or frequency. ${ }^{26}$ In this study, the feeding behaviors of parents were assessed with a 5 Likert-type scale format: 1(never), 2 (rarely), 3 (sometimes), 4 (most of the time), and 5 (always). The rating scores are summed up by total scale. These scales are easy to work with and are easily understood by respondents. With this type of scale, an item is presented as a declarative sentence, followed by response options that indicate various degree of frequency from never to always. The higher the score is the better feeding behaviors of parents are. The examples of the items are presented in table 1.

Content validity by expert review: After generating pool items, the initial item pool that consisted of 70 items was submitted to obtain review and critique by experts' panel to ensure that the items represented critical attributes of the parental feeding behaviors of parents with toddlers and to establish the scale's content validity. The aim of 
content validity test was to eliminate irrelevant items from the instrument totally, and to re-phrase or supply new wording for items related to the measured construct where necessary. ${ }^{27}$ The outcome of the review finally validated the definition of the concepts. The total number of the experts in this study is six experts that include four experts in nursing field and two dieticians who are experts in community and clinical nutrition. They were asked to evaluate content validity of the PFBQ through the Content Validity Form by providing one to four-point scale in each item that would reflect the relevance of the operational definition and content domain: $1=$ not relevant, $2=$ somewhat relevant, $3=$ quite relevant, $4=$ very relevant. Each of the six experts individually evaluated the PFBQ. For a scale to be judged as having excellent content validity, a content validity index (CVI) was calculated, with criteria items CVI should be higher than .80 and the value of SCVI/ Ave should be .90 or higher. $^{28-30}$

Additionally, the experts were asked to evaluate the clarity of the item style related to the structural elements of the content review, for example ambiguous wording in the questions. They were asked to evaluate clarity of item style of the PFBQ using the form by providing one to four-point scale in each item that would reflect the clarity of the item style using the four-point rating scale: $1=$ not clear, $2=$ somewhat clear, $3=$ quite clear, $4=$ very clear. At the end of the content review, all experts were asked about the total of instrument to identify items that need to be added to the content domain or to be deleted because they do not represent the content domain. When experts did not agree, or when the panel identified missing domain area, the instrument was revised and reassessed. ${ }^{28}$

Pretest study: Pre-testing of the first draft of the PFBQ (80 items) was conducted to determine the initial internal consistency reliability of the subscales and the total instrument. This study was started after receiving the authorization letter from the Ethics Committee at the Faculty of Medicine, Universitas Gadjah Mada in September 2013.

Participants and procedure: A convenience sampling was employed in this study consisted of 30 parents having toddlers from both urban and rural areas in Yogyakarta with the same characteristics. The inclusion criteria included: being a mother or father, having a child aged between 12 to 36 months and having stayed with him/her for at least the past six months, being able to read and write Indonesian Language, having a clear home address, and willing to participate in the study. The exclusion criteria included parents having toddlers with the following problems: congenital or metabolic abnormalities affecting growth, serious food allergies, and eating disorder. Data were collected by researcher or research assistants. It was conducted in the integrated service post (local name: Paysandú) or home visits. Parents with toddlers would be asked to answer the questions that are related to feeding behaviors of parents to maintain adequate food intake for their toddlers. While answering the questionnaire, the respondent could refuse to answer the questionnaire whenever they want. Filling out the questionnaire took approximately 15-30 minutes. After finishing each data collection, the researcher and research assistants examined the questionnaires for data completeness.

Data analysis: Items analysis was used to select the best items using corrected item-total correlation, inter-item correlation and Cronbach alpha reliability before testing its construct validity on large sample. Regarding a common rule of thumb, the inter-item correlations should be $>.3$ but not too large $(<.8-.9)$ and the corrected item total correlation should be between .3 and .7. Cronbach's alpha coefficient of the first draft scale should be at least 0.7 for new developed instrument. ${ }^{31}$

\section{RESULTS}

\section{Content validation by experts review}

The results of the study show that the Content Validity Index of the Parental Feeding Behaviors Questionnaire (PFBQ) is I-CVI (.83-1.00) and S-CVI (.98). The result of the Content Validity Index of the Parental Feeding Behaviors Questionnaire (PFBQ) in each dimension is described in Table 2. Based on the result above, the data show that both content validity in the individual item and the overall scale meet Lynn's criteria, so it can be incorporated into the instrument. Additionally, the elements of the content review are the result of the agreement for item clarity. In this study, the item clarity is measured if it achieved $80 \%$ of agreement among experts. The result of the clarity agreement for total items is that $99.98 \%$ of the experts thought that the items in the instrument were clear. The summary of the agreement in each dimension is as follows (Table 3 ).

Table 1: The example of items in PFBQ.

\begin{tabular}{|c|c|c|}
\hline Dimension & No & Examples of Item \\
\hline \multirow{3}{*}{$\begin{array}{l}\text { Providing } \\
\text { healthy food }\end{array}$} & 1 & learn about toddlers' food \\
\hline & 2 & $\begin{array}{l}\text { will serve food that } \\
\text { suitable with toddlers' need }\end{array}$ \\
\hline & 3 & give foods for my child \\
\hline \multirow{2}{*}{$\begin{array}{l}\text { Enhancing } \\
\text { toddlers' good } \\
\text { eating }\end{array}$} & 1 & $\begin{array}{l}\text { ask how to enhance good } \\
\text { eating behaviour of } \\
\text { toddlers }\end{array}$ \\
\hline & 2 & motivate my child \\
\hline \multirow{3}{*}{$\begin{array}{l}\text { Provide a } \\
\text { pleasant } \\
\text { environment }\end{array}$} & 1 & $\begin{array}{l}\text { learn how to provide a } \\
\text { pleasant eating }\end{array}$ \\
\hline & 2 & $\begin{array}{l}\text { will keep calm and relax } \\
\text { although my child does not } \\
\text { eat }\end{array}$ \\
\hline & 3 & $\begin{array}{l}\text { provide appropriate } \\
\text { equipment/utensils for my } \\
\text { child }\end{array}$ \\
\hline
\end{tabular}


In this analysis, the researcher also used the suggestion from experts; the six experts proposed various comments and suggestions. There are several suggestions from expert to add more items that are related to emotional of parents during feeding based on Indonesian culture and the methods of parents to enhance good eating behaviors for their child. For example, first expert, a registered dietician who has been studying about parental feeding behaviors especially about parental style in the context of Indonesian culture, proposed that all items cover the feeding behaviors of parents, but it should add items that are related to the parenting style of Indonesian parents when they feed their toddlers because it is related to how parents provide food for their toddlers.

Table 2: Content validity index of the parental feeding behaviors questionnaire (PFBQ) based on each dimension $(\mathrm{N}=6)$.

\begin{tabular}{|llc|}
\hline DIMENSION & I-CVI & S-CVI/Ave \\
\hline Providing healthy food & $.83-1.00$ & .96 \\
\hline $\begin{array}{l}\text { Enhancing toddlers' eating } \\
\text { behaviours }\end{array}$ & $.83-1.00$ & .99 \\
\hline $\begin{array}{l}\text { Providing a pleasant } \\
\text { eating environment }\end{array}$ & $.83-1.00$ & .98 \\
\hline
\end{tabular}

Table 3: Percentage of the clarity agreement for items of the parental feeding behaviors questionnaire (PFBQ) based on each dimension $(\mathrm{N}=6)$.

\begin{tabular}{|lll|}
\hline Dimension & $\begin{array}{l}\text { Percentage } \\
\text { Clarity } \\
\text { Agreement }\end{array}$ & $\begin{array}{l}\text { Mean Percentage } \\
\text { Clarity Agreement }\end{array}$ \\
\hline $\begin{array}{l}\text { Providing healthy } \\
\text { food }\end{array}$ & $83 \%-100 \%$ & $99 \%$ \\
\hline $\begin{array}{l}\text { Enhancing toddlers } \\
\text { eating behaviour }\end{array}$ & $83 \%-100 \%$ & $98 \%$ \\
\hline $\begin{array}{l}\text { Providing a pleasant } \\
\text { eating environment }\end{array}$ & $83 \%-100 \%$ & $99 \%$ \\
\hline
\end{tabular}

For instance, parents get angry when their child does not finish the whole meal or they do not care whether their child finishes the whole meal or not. For the other experts, they suggested to reconsider who is the target population, corrected some items semantically including ambiguous term, avoided misunderstandings with the two terms in the question, and also added several items that are related to safe food for example about the activities that are related to identify the expired date before buying foods, modify food, and obtain information from electronic media. Based on the result, it was concluded that there are no item that was deleted because all items represented the domain of the parental feeding behaviors and ten items were added which comprised three items in the first dimension (provide healthy food) 'will identify the expired date of foods', 'give balanced food ' and ' don't care about what toddlers consumed'; five items in the second dimension (enhance good eating) 'keep updated on how to enhance eating behaviors', 'will teach toddlers', modify the food shape', 'give the foods although refused ', and 'motivate toddlers to finish the whole meal'; and two items in the third dimension (provide pleasant eating environment) which are 'provide appropriate equipment/utensils' and 'get angry during mealtimes'.

\section{Table 4: Demographic characteristic of the} participants in the pre-test study.

\begin{tabular}{|c|c|c|c|}
\hline $\begin{array}{l}\text { Socio- } \\
\text { demographic } \\
\text { characteristic }\end{array}$ & Mean \pm SD & $\begin{array}{l}\text { Number } \\
(n=30)\end{array}$ & $\begin{array}{l}\text { Percentage } \\
(\%)\end{array}$ \\
\hline \multicolumn{4}{|l|}{ Children: } \\
\hline Age (month) & $25.90 \pm 6.62$ & & \\
\hline \multicolumn{4}{|l|}{ Age: } \\
\hline$<12$ months & & 6 & 20 \\
\hline $12-<24$ months & & 21 & 70 \\
\hline $24-36$ months & & 3 & 10 \\
\hline \multicolumn{4}{|l|}{ Gender: } \\
\hline Male & & 13 & 43.33 \\
\hline Female & & 17 & 56.67 \\
\hline \multicolumn{4}{|l|}{ Parents: } \\
\hline Age & $28.33 \pm 6.11$ & & \\
\hline \multicolumn{4}{|c|}{ Parents' Age (year): } \\
\hline$<18$ & & 6 & 1.10 \\
\hline $18-40$ & & 509 & 92.88 \\
\hline$>40$ & & 33 & 6.02 \\
\hline \multicolumn{4}{|c|}{ Total number of children } \\
\hline 1 & & 17 & 56.67 \\
\hline 2 & & 10 & 33.33 \\
\hline 3 & & 3 & 10 \\
\hline \multicolumn{4}{|c|}{ Family member live in the household } \\
\hline Yes & & 15 & 50 \\
\hline No & & 15 & 50 \\
\hline \multicolumn{4}{|c|}{ Socio economic status } \\
\hline Low & & 18 & 60 \\
\hline Middle & & 9 & 30 \\
\hline High & & 3 & 10 \\
\hline \multicolumn{4}{|l|}{ Education } \\
\hline Low & & 2 & 6.67 \\
\hline Middle & & 23 & 76.67 \\
\hline High & & 5 & 16.66 \\
\hline \multicolumn{4}{|l|}{ Occupation } \\
\hline Unemployed & & 27 & 90 \\
\hline Employed & & 3 & 10 \\
\hline \multicolumn{4}{|c|}{ Health education about toddlers' nutrition } \\
\hline Yes & & 12 & 40 \\
\hline No & & 18 & 60 \\
\hline
\end{tabular}

Based on the feedback from all of the expert panel members, of the original 70 items, there were 16 revised items and 10 added items. After validating the content, 80 items were put in the first draft of the PFBQ which was used in the pre-test study. 


\section{Pre-test study}

\section{Participants characteristic:}

On the pre-test study $(\mathrm{n}=30)$, all subjects were mothers of toddlers, and they had an average age of 28.33 years $(\mathrm{SD}= \pm 6.11)$. Most of the respondents were middleeducated $(76.67 \%)$ and household mother $(90 \%)$. More than half of the respondents $(60 \%)$ never got health education about toddlers' nutrition. A half of respondents lived with other family member in the household $(56.67 \%)$. Also nearly a half of respondents had at least one child $(56.67 \%)$. The average age of the toddlers was 25.90 months $(\mathrm{SD}= \pm 6.62)$ and more than half of them $(56.67 \%)$ were female (Table 4$)$. The results of item analysis were presented as follows:

Inter-item correlation: Based on the result of SPSS output, it was shown that most of the items had acceptable inter-item correlation value (> .3). The item 9 "will make "home-prepared foods" as often as possible to prevent foodborne illness' and item 11 ' will identify the sources of harmful substances in food consumed by my child ' have score $>.80$, but the researcher did not delete both items because there did not have similar meaning. In item ' 9 ' focusing on the prevention of foodborne illness is related to behaviors of parents to make decision to provide healthy and safe food for their toddlers. It is important behaviors recently although parents were aware of food hygiene and safety but many parents purchase ready-to-eat food for children's meals, because there are many food vendors in their neighbourhood and it is more practical to buy a meal from the food vendors.

\section{Table 5: Item-total correlation and Cronbach Alpha} coefficient $(n=30)$.

\begin{tabular}{|llll|}
\hline Dimension & $\begin{array}{l}\text { Number of } \\
\text { items }\end{array}$ & $\begin{array}{l}\text { Item-Total } \\
\text { Correlation }\end{array}$ & $\begin{array}{l}\text { Cronbach's } \\
\text { Alpha } \\
\text { Coefficient }\end{array}$ \\
\hline $\begin{array}{l}\text { Providing } \\
\text { healthy food }\end{array}$ & 19 (PF1- PF19) & $.305-.567$ & .90 \\
\hline $\begin{array}{l}\text { Enhancing } \\
\text { toddlers } \\
\text { eating } \\
\text { behaviours }\end{array}$ & $26(\mathrm{EE} 1-\mathrm{EE} 26)$ & $.307-.625$ & .86 \\
\hline $\begin{array}{l}\text { Providing a } \\
\text { pleasant } \\
\text { eating } \\
\text { environment }\end{array}$ & 11 (PE1-PE11) & $.431-.5576$ & .86 \\
\hline Total & 56 & & \\
\hline
\end{tabular}

Meanwhile, although item ' 11 ' also focuses on foodborne illness but this item is to evaluate how parents will make decision to concern about the sources of harmful substances in food for example food additives and preservatives and the quality of food, because In Indonesia, parents prefer to buy food that was cheap without being aware that the food would affect the future health of their children. The largest correlation coefficient was found between item 'will prepare equipment/utensils (66)' and item 'provide appropriate equipment/utensils (72)' (inter-item correlation= 0.833 ). Both items focus on eating environment during feeding that should be pleasant and supportive for healthy eating habits. Both items describe that appropriate equipment and utensils foster independence by allowing children to serve themselves in different operation which is transitional and productive operation, respectively. Probably, it made parents got confused because both items had similar meaning too. Since both two items were too similar, item 72 was deleted. And to evaluate parents' behaviors that represent parents' activities to provide pleasant eating environment, there is still one item number 53 to cover all aspects in operational definition.

Item-total correlation: Based on the result of SPSS output in first analysis, item-total correlations for the parents feeding behaviors scales ranged from .305 to .625 . In the feeding behaviors scale, $71 \%$ of the items are correlated with the total scores at a level of above .30 . There are 23 item-to-total correlations which are below .30 and five of them are negatively correlated. Therefore, all items (23 items) were deleted because of the low correlations (<.30). And in the second analysis, only item ' 16 ' had low correlation. From the result of the observation when parents answered the question, the subjects had no difficulty in understanding the items with positive questions (they didn't feel difficult to answer the question and had a good motivation to answer the question); in contrast, several parents felt confused to answer negative questions and needed more time to read the question. The range of time consumed to answer the question was around 15-40 minutes.

Reliability: For assessing internal consistency, Cronbach's alpha coefficient was used. Cronbach's alpha coefficient for the 56 items in PFBQ is .94; .90 for providing healthy food dimensions; .86 for enhancing toddlers' good eating behavior dimensions; and .86 for providing pleasant eating environment dimensions. The Cronbach's alpha coefficient ranges from .86 to .94, indicating an achieved minimum reliability of .70 for the new instrument. Based on this result, the revised 56 items instruments can be used in the large study to test psychometric properties (Table 5).

\section{DISCUSSION}

In initial examination, the PFBQ was constructed to measure the feeding behaviors of Indonesian parents to maintain adequate food intake for their toddlers. This instrument provides all dimensions of the parental feeding behaviors as a new perspective to measure feeding behaviors of parents with toddlers. By reviewing literature, there was a lack of clarity regarding definitions and measurement of the parental feeding behaviour based on nursing perspective and others health profession. ${ }^{32-33}$ The most existing definitions of the parental feeding behaviors were closely related to parenting, parenting 
eating, and feeding practice. ${ }^{28-29}$ Comparing the constructs of the PFBQ scale with the parental feeding behaviors, an instrument was used to measure parental feeding concept in various populations. It was found that almost all existing instruments emphasized on parental feeding activities or psychomotor activities that focus on the activities or strategies that parents use to manage how much, when and what children eat such as on parental use of control in feeding. ${ }^{15-18}$ There was a lack of construct involved in cognitive activities that reflected acquiring and gathering information and making judgment and decision. Although Birch, et.al, (2001) and Jansen, et.al., (2012) state that the feeding behaviors of parents are attitudes and strategies regarding the control of children eating, it means that the parental feeding behaviors consist of cognitive action (attitude) and psychomotor action (strategy) but they only focus on the attitude and strategy regarding parents control in children eating or general atmosphere of emotion in the interaction between parents and children during the meal situation. ${ }^{15}$ Therefore, it did not encompass other parental feeding behaviors such as finding resources and gathering information about toddlers nutrition, planning appropriate food, giving balanced food, and modifying food which are important activities during maintaining adequate intake of food for their toddlers.

In this study, the PFBQ is a comprehensive parental feeding behaviors instrument used to measure overall aspects of the parental feeding concept through three kinds of behaviors that are related to provide healthy food; to enhance toddlers' good eating behaviors; and to provide pleasant eating environment. For example, acquiring and gathering information activities involve acquiring and gathering information about healthy food for toddlers; the characteristic of toddlers' eating behavior; and eating environments that are pleasant for toddlers. In the construction phase of the development of this questionnaire, the content validity index (CVI) was determined as evidence for content validity. The result of CVI indicated that the PFBQ is acceptable for content validity, and then it is accepted to represent the concept of parents feeding behaviors of toddlers. In other word, content validity is supportive to confirm the adequacy of the content representativeness of the scale for measuring what the researcher intended to study. ${ }^{31}$ Based on the result of initial internal consistency reliability in the pretest study, it showed that 56 items in the PFBQ had a good reliability or internal consistency exists. All things are considered, which are consistently representing the construct of parental feeding behaviors. The pre-test study can be conducted to; 1) determine the number of items taken to complete the scale, 2) establish the scale if the instructions were unclear, and 3) identify clarity and appropriateness of scale used if participants found anything objectionable or inappropriate about the scale. ${ }^{34}$ In addition, when considering the item statements, the PFBQ scale was a practical measure which reflects specific questions on actual behaviors emerging in the activities of Indonesian parents to maintain adequate food intake for their toddlers that can easily recall and answer.

This study is the preliminary result of the PFBQ development that is related to parents feeding behaviors in Indonesia. Because there are several instruments to measure parental feeding behaviors of toddlers, none of them is developed for Indonesian parents of toddlers. And also, none of them is developed in regards that the feeding behaviors of parents composed of acquiring and gathering information activities; making judgment and decision activities; and taking action activities that are related to providing healthy food; enhancing toddlers good eating behaviour; and providing pleasant eating environment. However, this preliminary result is the first step to develop instrument which it needs for the next steps to determine the dimensionality of a scale through factor analysis with large sample. The PFBQ is as a potentially acceptable instrument to measure parents feeding behaviors that leads to be a useful guideline for evaluating feeding behaviors of parents with toddlers.

\section{ACKNOWLEDGEMENTS}

I would like to thank the parents who participated in this study for their willingness to give their time to complete the questionnaire.

\section{Funding: No funding sources \\ Conflict of interest: None declared}

Ethical approval: This study was approved by Medical and Health Research Ethics Committee (MHREC), of the Faculty of Medicine Gadjah Mada University. (Approval Letter No. Ref: KE/FK/808/EC, dated 9 September 2013)

\section{REFERENCES}

1. Lutter CK, Daelmans BMEG, de Onis M, Kothari MT, Ruel MT, Arimond M, Borghi E. Undernutrition, poor feeding practices, and low coverage of key nutrition interventions. Pediatrics. 2011;128(6):e1418-27.

2. Word Health Organization. Strengthening action to improve feeding of infants and young children 6-23 months of age in nutrition and child health programmes. In strengthening action to improve feeding of infants and young children 6-23 months of age in nutrition and child health programmes. Geneva: WHO Press; 2008.

3. Ministry of Health. Republic of Indonesia. Buku Sakut Asuhan Gizi di Puskesmas Pedoman Pelayanan Gizi bagi Petugas Kesehatan. Jakarta: Kementrian Kesehatan RI;2012.

4. Orem, D.E., Taylor, S.G., \& Renpenning, K.L. Nursing concepts of practices (6thedition). St. Louis: Mosby a Harcout Health Science;2001.

5. Savage JS, Fisher JO, Birch LL. Parental influence on eating behavior. J Law Med Ethics, 2008;35(1):22-34. 
6. Jansen, P. W., Roza, S. J., Jaddoe, V. W., Mackenbach, J. D., Raat, H., Hofman, A., Tiemeier, H. Children's eating behavior, feeding practices of parents and weight problems in early childhood: results from the population-based Generation $\mathrm{R}$ Study. Int J Behav Nutr Phys Act, 2012;9(1), 130. Doi:10.1186/1479-5868-9-130.

7. Rodgers, 2013 Rodgers, R. F., Paxton, S. J., Massey, R., Campbell, K. J., Wertheim, E. H., Skouteris, H., \& Gibbons, K. (2013). Maternal feeding practices predict weight gain and obesogenic eating behaviours in young children : a prospective study. Int J Behav Nutr Phys Act, 10(1), 1. Doi:10.1186/1479-5868-10-24.

8. Loth, 2013 Loth, A. K. A., \& Maclehose, R. F. Food-Related Parenting Practices and Adolescent Weight Status: A Population-Based Study. Pediatrics, 2013;131(5), 1443-1450. doi:10.1542/peds.2012-3073.

9. Moore, A. C., Akhter, S., \& Aboud, F. E. Responsive complementary feeding in rural Bangladesh. Soc Sci Med, 2006; 62(8), 1917-30. doi:10.1016/j.socscimed.2005.08.058.

10. Tschan Tschann, J. M., Gregorich, S. E., Penilla, C., Pasch, L. a, de Groat, C. L., Flores, E., Butte, N.F. Parental feeding practices in Mexican American families: initial test of an expanded measure. Int $\mathbf{J}$ Behav Nutr Phys Act, 2013;10(1), 6. doi:10.1186/1479-5868-10-6.

11. Arcan, C., Neumark-Sztainer, D., Hannan, P., Berg, P., Story, M., \& Larson, N. Parental eating behaviors, home food environment and adolescent intakes of fruit, vegetables and dairy foods: longitudinal findings from project EAT. Pub Health Nutr, 2007;10,1257-1265.

12. Birch, L.L., \& Fisher, J.O. Mothers' child feeding practices influence daughters' eating and weight. Am J Clin Nutr, 2000;71,1054-1061.

13. Sandefur, G.D., \& Meier, A. The family environment: structure, material resources, and child care. In: Brown B, ed. Key Indicators of Children and Youth Well-being. New York: Lawrence Erlbaum Associates; 2008:237-257.

14. Moore, J. B., Pawloski, L., Baghi, H., Whitt, K., Rodriguez, C., Lumbi, L., \& Bashatah, A. Development and examination of psychometric properties of Self-Care instruments to measure nutrition practices for English and Spanishspeaking adolescents. Self -Care and Dependent Care Nursing: The Official Journal of the International Orem Society, 2005;13(1), 9-17.

15. Birch, L.L., Fisher, J.O., Grimm-Thomas, K., Markey, C.N., Sawyer, R., \& Johnson, S.L Confirmatory factor analysis of the child feeding questionnaire: a measure of parental, attitude, beliefs and practices about child feeding and obesity proneness. Appetite 2001;36, 201-210.

16. Musher-Eizenman, D.R, \& Holub, S.C. Comprehensive feeding practices questionnaire: validation of a new measure of parental feeding practices. J Pediatr Psycho. 2007;32(8):960-72.

17. Hodges, E.A., Houck, G.M., Kindermann, T. Validity of the nursing child assessment feeding scale during toddlerhood. West J Nurs Res. 2007;31:662-78.

18. Ha PB., Bentley ME, Pachon H, Sripaipan T, Caulfield LE, Marsh DR, Scroeder DG. Caregiver styles of feeding and child acceptance of food in rural Viet Nam. (Supplemental material). Food and Nutrition Buletin. 2002; 23(4), 92-98.

19. DeVellis. Scale Development. Theory and Applications (2nd Ed.). USA: Sage Publication, Inc; 2003.

20. Mishel MH. Methodological studies: Instrument development. In P.J. Brink \& M.J. Wood (Eds.). Advanced design in nursing research. (2nded.). Thousand Oaks, CA: SAGE; 1998.

21. Benson J, Clark F. A Guide for Instrument Development and Validation. The American Journal of Occupational Therapy. 1992; 36(12), 789-800.

22. Wynd, C.A., Schmidth B., \& Schaefer, M.A. Two quantitative approaches for estimating content validity. West J Nurs, 2003; 25, 508-517.

23. Taylor, S.G., Renpenning, K.E., Geden, E.A., Neuman, B.M., \& Hart, M.A. A Theory of Dependent-Care: A corollary theory to Orem's theory of self-care. Nurs Sci Q 2001;14(1), 39-47.

24. Weaver, L. Feeding the normal infant, child and adolescent. The Medicine Publishing Company Ltd, 38-42, 2003.

25. Worthington-Roberts, B.S., \& Williams, S.R. Nutrition Throughout the life cycle. Singapore: McGraw-Hills Companies, 2000.

26. Burns, N., \& Grove, S.K. The Practice of Nursing Research. Conduct, Critique, \& Utilization (4th Edition). Philadelphia: W.B. Saunders, 2001.

27. Chaiyawat, W., \& Brown, J. Psychometric properties of the Thai versions of State-Trait anxiety inventory for children and child medical fear scale. Res Nurs Health, 2000, 23, 406-414

28. Lynn, M. Determination and Quantification of content validity. Nurs Res 1986;35,382-385.

29. Hair, J.F., Black, W.C., Babin, B.J., \& Anderson, R.E. Multivariate data analysis: a global perspective (7th Ed). Boston: Pearson, 2010.

30. Polit, D.F., \& Beck. C.T. Nursing Research. Principles and Methods (Seventh Edition). Philadelphia: Lippincott Williams \& Wilkins, 2004.

31. Nunnally, J., \& Bernstein, I. Psychometric Theory (third edition). New York: McGraw Hill, 1994.

32. DiSantis, K. I., Hodges, E. A., Johnson, S. L., \& Fisher, J. O. The role of responsive feeding in overweight during infancy and toddlerhood: A systematic review. Int J Obesity, 2011;35, 480-492. DOI: 10.1038/ijo.2011.

33. Hennessy E, Hughes, Goldberg JP, Hyatt RR. Parent behaviour and child weight status among a diverse group of underserved rural families. Appetite. 2010;54:369-77. 
34. Pett MA, Lackey NR, Sullivan JJ. Making sense of factor analysis: the use of factor analysis for instrument development in health care research. Thousand Oaks, CA: Sage Publications, 2003.
Cite this article as: Lusmilasari L, Chaiyawat W, Rodcumdee B. The development of the parental feeding behaviours questionnaire for Indonesian parents with toddlers: preliminary result. Int J Community Med Public Health 2015;2:558-65. 